\title{
Self-Concept, Gender, And Product Type: An Investigation Of Brand Loyalty
}

Joseph F. Rocereto, Monmouth University, USA

Joseph B. Mosca, Monmouth University, USA

\begin{abstract}
Numerous studies have investigated the impact of self-concept brand image congruity on brand loyalty. However, there is a dearth of literature which has assessed this relationship across different product types. Furthermore, there is a lack of understanding regarding the role that gender may play in the creation of such brand loyalty. This study investigates the effects of selfconcept brand image congruity on consumer attitude formation and resulting brand loyalty across two different types of products (i.e., hedonic and utilitarian products) and assesses the moderating role of gender within each product type setting. Results reveal that the proposed model is sufficiently robust to explain the effects of self-concept brand image congruities across different product types. Furthermore, this study indicates that gender serves as a moderator in both product type settings, however, in theoretically important different manners.
\end{abstract}

Keywords: Self-Concept; Brand Image; Loyalty; Gender; Hedonic; Utilitarian

\section{INTRODUCTION}

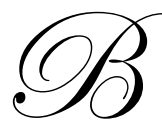

rand loyalty has received much attention in academia as well as among business professionals (Dick and Basu 1994; Oliver 1999; Srinivasan, Anderson and Ponnavolu 2002). Increasing customer retention through customer loyalty programs can be an important competitive advantage for sellers. Loyal customers who continually repurchase from the same provider may buy in greater quantities, be willing to pay price premiums, and are usually less costly to serve (Zeithaml, Berry and Parasuraman 1996).

To date, much of the attention afforded to the study of brand loyalty has dealt with the behavioral and/or attitudinal components of consumers from a strategic marketing perspective, focusing on various elements of the marketing mix that might be utilized to encourage customer loyalty. Some researchers suggest that consumer behavior alone (i.e. repurchasing behavior) can be sufficient to identify loyal customers (Cunningham 1966; Kahn, Kalwani and Morrison 1986; Tellis 1988). Others argue that such consumer behavior must be accompanied by and embedded in an attitudinal component, based upon the cognitive-affective-conative tricomponent attitude model, that serves as the engine that drives consumer loyalty behavior (Day 1969; Dick and Basu 1994; Oliver 1999).

Still, few articles have directly focused on the roles that certain consumer variables or product characteristics might play in the creation and sustentation of attitudinal customer loyalty (for possible exceptions see Fournier 1998; Grubb and Grathwohl 1967; Richins 1994). In order to better understand how brand loyalty is created in consumers, it is important to examine customer loyalty issues from the perspective of the consumer as well as from that of the firm. One such phenomenon that has received attention in consumer behavior literature is the notion of self-concept brand image congruity (Belk 1988; Grubb and Grathwohl 1967; Richins 1994; Wallendorf and Arnould 1988). Self-concept brand image congruity can be defined as the degree to which an object is viewed by its owner as symbolizing aspects of one's self. The "self" can be described conceptually through self-concept theory, which states that the behavior of humans can be strongly influenced by the formation and maintenance of one's own "self-concept" (Wylie 1961). In regards to brand loyalty, due to the intimate nature of one's established self-concept, this consumer-object identification link can elicit affective responses towards the object on behalf of the consumer (Ball and Tasaki 1992), thereby increasing the potential for the establishment of attitudinal customer loyalty (Oliver 1999). 
However, it is theoretically important to investigate whether this congruity construct affects consumer attitude and resulting brand loyalty in similar ways across varying types of products, particularly between product types that are inherently high in affective dimensions (i.e., hedonic products) and those that are low in affective dimensions (i.e., utilitarian products). Furthermore, a multitude of research shows that gender differences can impact the relative strengths of relationships between marketing variables. Therefore, it is also prudent to assess the potential moderating role of gender in such brand loyalty creation.

In summary, the purpose of the current study is three-fold: (1) to propose and empirically test a model of brand loyalty that results from the effects of self-concept brand image congruity on consumer attitude; (2) to test the robustness of this model by examining its model fit between two different product types (i.e., hedonic versus utilitarian products); and (3) to assess the differential moderating role of gender within the proposed model across product types.

\section{Brand Congruity}

A multitude of researchers have investigated the premise that individuals strive to create and sustain a selfidentity (Ball and Tasaki 1992; Belk 1988; Grubb and Grathwohl 1967; James 1890; Sirgy and Samli 1985; Wallendorf and Arnould 1988). Results of these studies have indicated that it is paramount for human beings to possess a sense of whom they are as individuals and have guided the conceptualization of self-concept theory. Authors have proposed various definitions of one's self-concept but are in general agreement on the basis of one's self-concept in that it assists individuals in defining themselves as distinct objects or subjects. James (1890) is commonly referred to as the founding father of self-concept theory and proposes that one's self-concept can be conceptualized as (James 1890, p. 291), “... a man's self is a sum of all that he can call his, not only his body and psychic powers, but his clothes and his house ...". This implies that one's view of one's self extends beyond his or her personal being and includes possessions and other external elements, as has been supported by subsequent authors (Belk 1988).

A primary interest involving the marketing-related effects of self-concept theory arises from the importance of which an individual places on one's own self-concept, and the degree to which one will expend energy and effort to preserve this "image" of one's self. Grubb and Grathwohl (1967) contend that one's self-concept is extremely valuable to an individual and must be "safe-guarded" and to be made still "more valuable". From a marketing perspective, studies have found that consumer attitudes and behaviors can be directed toward protecting and enhancing one's self-concept (Wallendorf and Arnould 1988). Specifically, consumers are likely to surround themselves with objects or frequent retail establishments whose images are congruent with their own self-concepts in an effort to bolster their self-concepts (Grubb and Grathwohl 1967; Sirgy and Samli 1985).

Prior research has provided strong evidence that consumers utilize particular brands in order to strengthen their own self-concept (Grubb and Grathwohl 1967). Self-concept brand image congruity can be conceptualized as the degree to which the image of a brand mirrors that of the self-concept of an individual. The greater the perceived congruency between the image of a brand and important aspects of one's own self-concept results in heightened levels of self-concept brand image congruity. Consequently, the more strongly one identifies with a brand, then the greater will be their emotional tie to that brand.

Brand symbolism is at the heart of self-concept brand image congruity (Kleine, Kleine and Allen 1995; Richins 1994). Brand symbolism suggests that characteristics of particular brands might symbolize important aspects of an individual, thereby strengthening their own self-concept through ownership of such a brand (Richins 1994). In this way, consumers seek to bolster their own self-concept by surrounding themselves with possessions that reflect or symbolize their own self-concept (Grubb and Grathwohl 1967). The authors note that (Grubb and Grathwohl 1967, p. 26), "Therefore, the consuming behavior of an individual will be directed toward the furthering and enhancing of his self-concept through the consumption of goods as symbols". Wallendorf and Arnould (1988, p. 531) continue that, “... we derive our self-concept form objects".

The concepts inherent to self-concept brand image congruity imply that there exists special relationships between consumers and particular products that may elicit emotional or affective responses. Ball and Tasaki (1992) 
and Fournier (1998) focus on the existence of such relationships. Fournier (1998) contends that in order to understand loyalty issues, one must also consider the relationships between consumers and their brands. She argues that (Fournier 1998, p. 344), “... brands can and do serve as viable relationship partners". Furthermore, she suggests that, similar to relationships between two persons, the relationship between a consumer and a brand can evolve over time. As the relationship continues to grow (Fournier 1998, p. 346), “... each stage is one interval in a sequence of changes in type ... or level of intensity (e.g. an increase or decrease in emotional attachment [parentheses included]".

\section{The Impact of Product Type}

Consumers purchase hedonic and utilitarian products for vary different reasons. Hedonic products are purchased for the pleasure and fun which they provide (Dhar and Wertenbroch 2000). Therefore, the reasons for these purchases extend beyond the mere utility that any such product may provide. The fact that hedonic products are purchased, in part, for the pleasure which they provide asserts that these products are affect-laden. Such high levels of inherent affect are likely to result in strong emotional responses from their owners. Thus, hedonic products are likely to impact the affective component of consumer attitude in stronger ways than utilitarian products.

Utilitarian products, on the other hand, are primarily purchased for functional or instrumental needs (Voss et al. 2003) and are not inherently affect-laden. These purchase choices are likely to be dominated by consumer cognitive processes rather than consumer affect. Therefore, it is expected that consumer attitude formation regarding utilitarian products will result from a different process than for hedonic products. The fundamental question to address, then, is whether such differential attitudinal impacts of hedonic and utilitarian products are sufficiently strong to result in invariant relationships between, (1) consumer self-concept brand image congruity and consumer attitude; and (2) consumer attitude and resulting brand loyalty. On the contrary, the pervasive effects of consumer self-concept brand image congruity on consumer attitude may negate such differences in the face of varying product types.

\section{The Role of Gender}

It is important to assess the effects of gender when considering the impact of self-concept congruity constructs because of the role that gender serves in one's view of one's self. Previous literature has indicated that gender is a major component of consumer's self-concept, and that the need to express masculinity and femininity can be achieved via brand choice (Dolich 1969).

Additional differences between genders, particularly in the U.S., can be found in relationship theory. Cross and Madson (1997, p. 5) assert that, "The social, institutional, and cultural environment of the United States promotes development of independence and autonomy in men and interdependence and relatedness in women". These personal relational differences between gender may translate to differential consumer-brand relationships, due to the fact that consumers can and do have relationships with their brands (Fourneir 1998).

\section{Hypotheses}

\section{Similarities between Groups}

Although there are expected differences in the creation of brand loyalty between hedonic and utilitarian products, there are some basic similarities. The overall creation of brand loyalty is not likely to be moderated by product type, since in each case the final outcome is the establishment of consumer loyalty toward a particular brand. Therefore, the focal constructs in the creation of brand loyalty are likely to play similar roles between groups, resulting in the proposed model to be sufficiently robust to explain brand loyalty creation in both product settings. 


\section{Effects of Self-Concept Brand Image Congruity on Consumer Attitude}

Traditional proponents of attitudinal brand loyalty argue that a consumer's loyalty toward a brand must become embedded in all three states of one's attitude in order for consistent brand loyalty behaviors to emerge (Oliver 1999; Dick and Basu 1994). Typically, loyalty initially becomes embedded in the cognitive state of one's attitude. At this state, preference for one brand over all others is based upon cognitive beliefs regarding the relative superiority of a particular brand relative to alternatives. While prior research has found that self-concept brand image congruity results in affective responses towards the brand in question (Ball and Tasaki 1992), such positive emotional responses that are associated with self-concept brand image congruity are also likely to influence a consumer's cognitive beliefs regarding the superiority of the brand in question relative to other brands. Thus, our first hypothesis is formally stated as:

H1: Self-concept brand image congruity is positively associated with consumers' cognitive responses towards both hedonic and utilitarian brands.

It is likely that the emotional charge that arises from high levels of self-concept brand image congruity will increase the likelihood of consumer affective responses towards that brand. Additional rationale for the likelihood of self-concept brand image congruity resulting in affective responses can be found in consumer-brand relationship theory. Previous studies have revealed evidence that consumers are prone to engage in consumer-brand relationships with brands that they feel most closely resemble their own self-concepts (Fournier 1998). The result of such relationships is that these possessions are more affectively charged or cathected (Ball and Tasaki 1992; Belk 1988). Thus, our second hypothesis is formally stated as:

H2: Self-concept brand image congruity is positively associated with consumers' affective responses towards both hedonic and utilitarian brands.

\section{Attitudinal Effects}

As previously discussed, researchers who are proponents of attitudinal brand loyalty propose that the manifestation of attitudinal loyalty may progresses from the cognitive state to the affective state and, finally, to the conative state (i.e., behavioral intentions). Therefore, it is likely that positive cognitive responses that are due to self-concept brand image congruity effects will also positively influence one's affective responses towards the focal brand. A consumer who believes that a particular brand is superior to alternative brands, particularly in cases wherein such beliefs are fueled by the close perceived proximity of brand image and self-concept, may tend to form a liking towards that brand. In turn, high levels of affect towards a particular brand are likely to result in favorable behavioral intentions regarding the focal brand. Thus, our third and fourth hypotheses are formally stated as:

H3: Consumers' cognitive responses towards both hedonic and utilitarian brands are positively associated with consumers' affective responses towards such brands.

H4: Consumers' affective responses towards both hedonic and utilitarian brands are positively associated with consumers' behavioral intentions towards such brands.

\section{Consequences of Consumer Attitude}

Prior research has found that behavioral intentions, while failing to result in actual behavior in every instance, are reliable predictors of behavior (Oliver 1999). Furthermore, based upon the theory inherent to attitudinal loyalty, consumers whose loyalty to a particular brand is manifested in all three states of their attitudes are likely to engage in consistent brand loyalty behaviors (Oliver 1999; Dick and Basu 1994). Thus, our fifth hypothesis is formally stated as:

H5: Consumers' positive behavioral intentions towards both hedonic and utilitarian brands are positively associated with consumers' attitudinal brand loyalty behaviors towards such brands. 


\section{Difference between Groups: The Moderating Role of Gender}

The proposed model contains a self-concept domain (i.e., self-concept brand image congruity), an attitudinal domain (i.e., cognitive, affective, and conative), and consequences (i.e., brand loyalty). While the constructs in the overall model are expected to play similar roles in the creation of brand loyalty, gender is expected to serve as a moderator within different domains between the two product groups.

In the case of hedonic products, it has been discussed that these products are generally purchased for the pleasure that they provide, thus these types of products are affect-laden. Furthermore, a large body of research indicates that females are more attuned to their emotions than are males (Cross and Madson 1997; Gabriel and Gardner 1999). One explanation for this difference between males and females can be attributed to the differential socialization process to which young boys and girls are exposed. Research has shown that parents are more likely to share and discuss emotions with their daughters than they are with their sons (Dunn et al. 1987). Additionally, research suggests that parents are more likely to display a myriad of different emotions with their daughters than they are with their sons (Kuebli and Fivush 1992; Malatesta et al. 1989). The outcome of these differential experiences at a young age is that females tend to access their emotions and talk about them more than boys (Kuebli et al. 1995). Therefore, it is expected that, regarding products that are affect-laden (i.e., hedonic products), gender will moderate the relationship between affective and conative responses of consumer attitude. Thus, our sixth hypothesis is formally stated as:

H6: For hedonic products, gender will moderate the relationship between affective responses and conative responses. That is, this relationship will be stronger for females than for males.

Utilitarian products are generally purchased for the functionality that they provide above and beyond any pleasure-related benefits (Voss et al. 2003). Therefore, unlike hedonic products which are primarily purchased for the pleasure which they provide, it is expected that the absence of high levels of affect regarding utilitarian products will suppress any gender-related moderation in the attitudinal domain. This expectation is based upon the fact that products which do not result in higher levels of affect will lack the capability to "trigger' higher levels of affect towards such products in females than in males.

However, a growing body of research suggests that females tend to seek out close relationships with others to a greater extent than do males (Gabriel and Gardner 1999). For example, female's social interactions stress more cooperation, intimate friendships, and the desire to sustain interpersonal harmony, while males social interactions are more likely to be characterized by dominance and competiveness (Maccoby 1990). This type of interdependent self-construal that is more common in females than in males can have implications regarding how one assesses one's own self-concept. These types of individuals (i.e., females) are more likely to include social relationships as a component of their own self-concepts (Markus and Kitayama 1991), directly linking others with their own selfconcepts (Gabriel and Gardner 1999).

By extending this personal relationship theory to consumer-brand relationships, it is expected that gender will emerge as a moderator in the self-concept domain regarding consumer-brand relationships. Since greater perceived levels of self-concept congruity between two individuals can lead to closer personal relationships, it is expected that females will seek closer consumer-brand relationships with utilitarian products than will males, utilizing self-concept brand image congruity as a mechanism to attain such closeness. Thus, our final hypotheses are formally stated as:

H7a: For utilitarian products, gender will moderate the relationship between self-concept brand image congruity and cognitive responses. That is this relationship will be stronger for females than for males.

H7b: For utilitarian products, gender will moderate the relationship between self-concept brand image congruity and affective responses. That is, this relationship will be stronger for females than for males.

Figure 1 presents the overall conceptual model for this study. Although we do expect the structural model to be invariant across product type, we also expect gender to moderate the relationships between hypothesized constructs within each product type setting. 


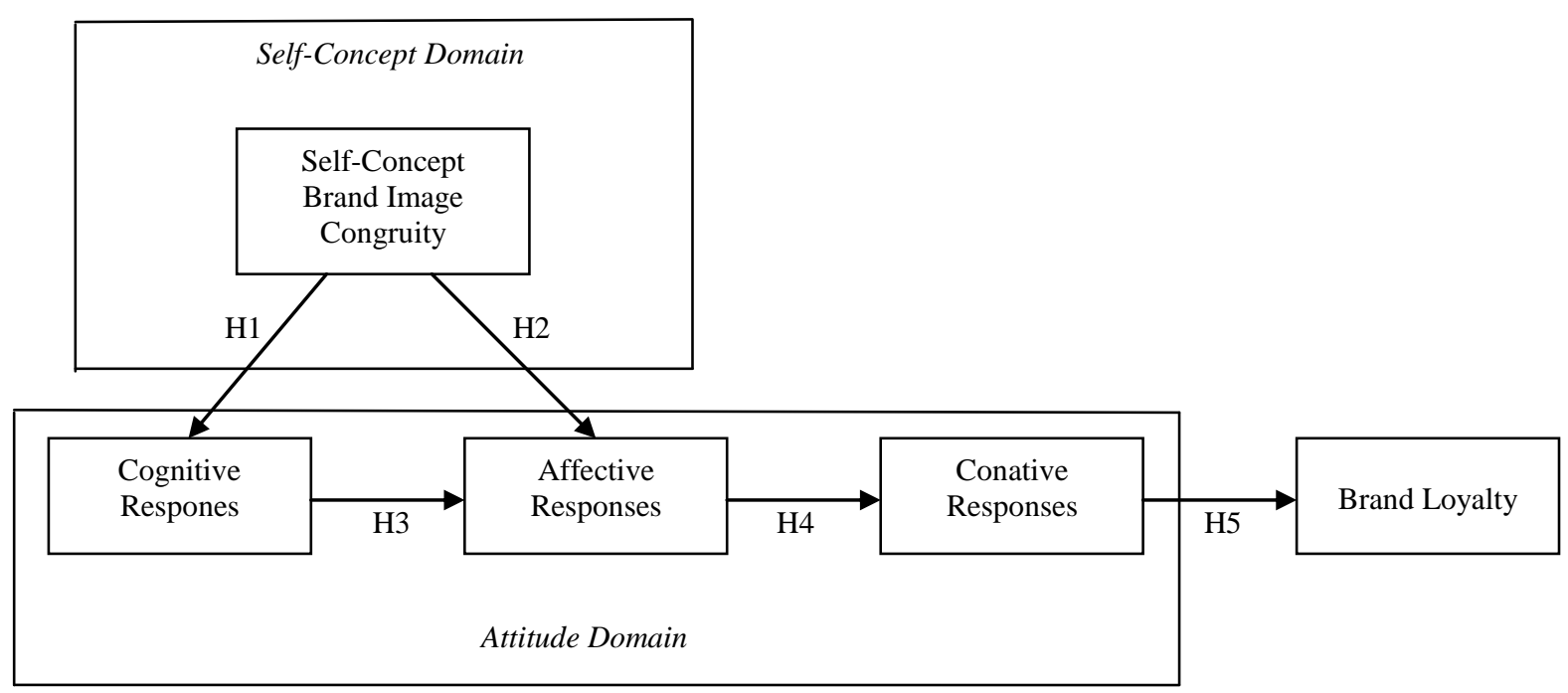

Figure 1: Conceptual Model for Hedonic and Utilitarian Products

\section{METHOD}

\section{Sample}

Surveys were simultaneously administered to two individual samples. One sample used a hedonic product as its setting and the other utilized a utilitarian product as its setting. Survey questions were identical between groups and included questions regarding consumer self-concept brand image congruence, consumer attitude, and brand loyalty behaviors. A convenience sample of 90 undergraduate business students at a Northeast U.S. university was used to comprise the hedonic product sample. Also, a convenience sample of 86 undergraduate business students from the same university was used in the utilitarian product setting. Past studies have utilized students in consumption - related investigations due to their general purchase knowledge and shopping experiences (Cole and Sherrell 1995), as well as in self-concept congruity settings (Hong and Zinkhan 1995).

\section{Measures}

Past literature has identified denim jeans to be a hedonic product (Voss at al. 2003). Therefore, denim jeans were chosen as the setting for the hedonic sample. Wallets were selected to be utilized as the setting for the utilitarian sample. Wallets were chosen for three reasons. First, wallets are considered a type of a clothing and apparel product in order to be consistent with the hedonic product chosen for the hedonic sample. Second, the range of prices for various types of wallets is similar to that of denim jeans. Thirdly, university students have extensive experience in both the purchasing and use of wallets as well as denim jeans.

Prior to the administration of the main survey, a pretest comprised of 32 students who are representative of the main samples was used to confirm the suitableness of using each product for their respective product-type samples. An eight-item semantic differential scale that measures the hedonic and utilitarian dimensions of products was adopted from Voss et al. (2003) for this purpose. Results show that jeans rate high on hedonic dimensions while wallets rate high on utilitarian dimensions $(\mathrm{p}<.05)$.

Participants were presented with a scenario that they had just realized that they had a need to purchase a new pair of denim jeans (i.e., hedonic sample) or a new wallet (i.e., utilitarian sample). They were then asked to identify their most preferred brand of denim jeans or wallets. All measurement items that were used to measure the constructs of interest pertained to their most preferred brand of denim jeans and wallets per sample. 
All measurement items used to measure the constructs of interest utilized 7-point Likert-type scales $(1=$ "strongly disagree"; 7 = "strongly agree"). Hypotheses H1 through H5 were tested using structural equation modeling (SEM). It is important to use reliable instruments when using SEM, so construct scales reliabilities were assessed by using Chronbach's alpha or Pearson's correlation coefficient, where appropriate. The scales to measure each construct were identical across studies. Five items were used to measure self-concept brand image congruity (hedonic sample: alpha $=0.89$; utilitarian sample: alpha $=0.93$ ). Two items were used to measure cognitive responses (hedonic sample: $r=0.35, p<0.01$; utilitarian sample: $r=.46, p<0.01$ ). Three items were used to measure affective responses (hedonic sample: alpha $=0.83$; utilitarian sample: alpha $=0.90$ ). Two items were used to measure behavioral intentions (hedonic sample: $r=.30, p<0.01$; utilitarian sample: $r=.58, p<0.01$ ). Two items were used to measure loyalty behaviors (hedonic sample: $r=0.45, p<0.01$; utilitarian sample: $r=0.47, p<0.01$ ). All measurement items are listed in Appendix. Construct correlations, means, and standard deviations are reported in Table 1.

Table 1: Construct Correlations, Means, and Standard Deviations

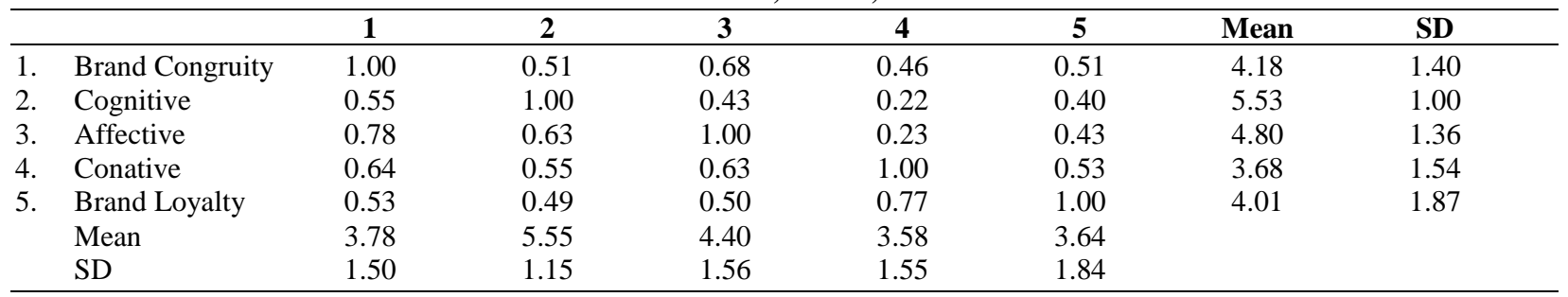

Note: Descriptions for the hedonic product are above the diagonal whereas descriptions for the utilitarian product are below the diagonal.

\section{Analysis and Results}

Hypotheses H1 through H5 were tested using SEM utilizing covariance matrices. For each sample, common structural equation modeling fit indices were calculated to assess model fit: Normed Fit Index (NFI), NonNormed Fit Index (NNFI), Comparative Fit Index (CFI), Incremental Fit Index (IFI), along with the traditional measure of model fit, chi-square fit. Given the fact that the chi-square test statistic is very sensitive to multivariate normality and produces unstable results with the violation of this basic assumption, researchers have been advised to use other fit indices (Gerbing and Anderson 1993).

Although the conventional chi-square value was significant $(p<0.05)$ for both samples, other fit indices show an acceptable model fit for both samples: for denim jeans: $x^{2}(72)=138.94, p<0.05, \mathrm{NFI}=0.90, \mathrm{NNFI}=0.93$, $\mathrm{CFI}=0.94$, IFI $=0.94$, and for wallets: $x^{2}(72)=105.31, p<0.05, \mathrm{NFI}=0.95, \mathrm{NNFI}=0.98, \mathrm{CFI}=0.98, \mathrm{IFI}=0.98$. As expected, the data shows that hypotheses H1 through H5 were significant $(p<0.05)$. Thus, the results show that the model is sufficiently robust to fit both product types. Figure 2 presents the empirical findings for both product types.

Multiple regression, with the use of interaction terms, was used to test hypotheses H6 through H7b. H6 posited that, for hedonic products, gender would moderate the relationship between affective and conative responses, with this relationship being stronger for females than for males. In order to test for this effect, first, affective responses was modeled as the independent variable with conative responses modeled as the dependent variable. Regression results showed a significant relationship $(\beta=0.23, t=2.18)$. Next, the interaction term, genderXaffect was modeled as an independent variable along with affective responses, with conative responses remaining as the dependent variable. Results show that the interaction term was significant $(\beta=0.26, t=2.33)$. Thus, H6 is supported.

H7a stated that, in the case of utilitarian products, gender would moderate the relationship between selfconcept brand image congruity and cognitive responses, with this relationship being stronger for females than for males. The same regression procedures were used to test for this moderation effect as were used to test H6. Again, 
the results reveal such moderation effects. Self-concept brand image congruity, as the independent variable, was found to be statistically related to cognitive responses $(\beta=0.55, t=6.00)$, and the interaction term, genderXselfconcept brand image congruity, when inserted into the model as a second independent variable, was also significant $(\beta=0.317, t=3.15)$. Thus, H7a is supported.

$\mathrm{H} 7 \mathrm{~b}$ stated that, in the case of utilitarian products, gender would also moderate the relationship between self-concept brand image congruity and affective responses. Using the same regression procedures, gender emerges as a moderating variable in this relationship. Self-concept brand image congruity was found to be a predictor of affective responses $(\beta=0.78, t=11.26)$, and the interaction term, genderXself-concept brand image congruity, was found to be significant when entered into the model as a second independent variable $(\beta=0.18, t=2.36)$. Thus, $\mathrm{H} 7 \mathrm{~b}$ is also supported.

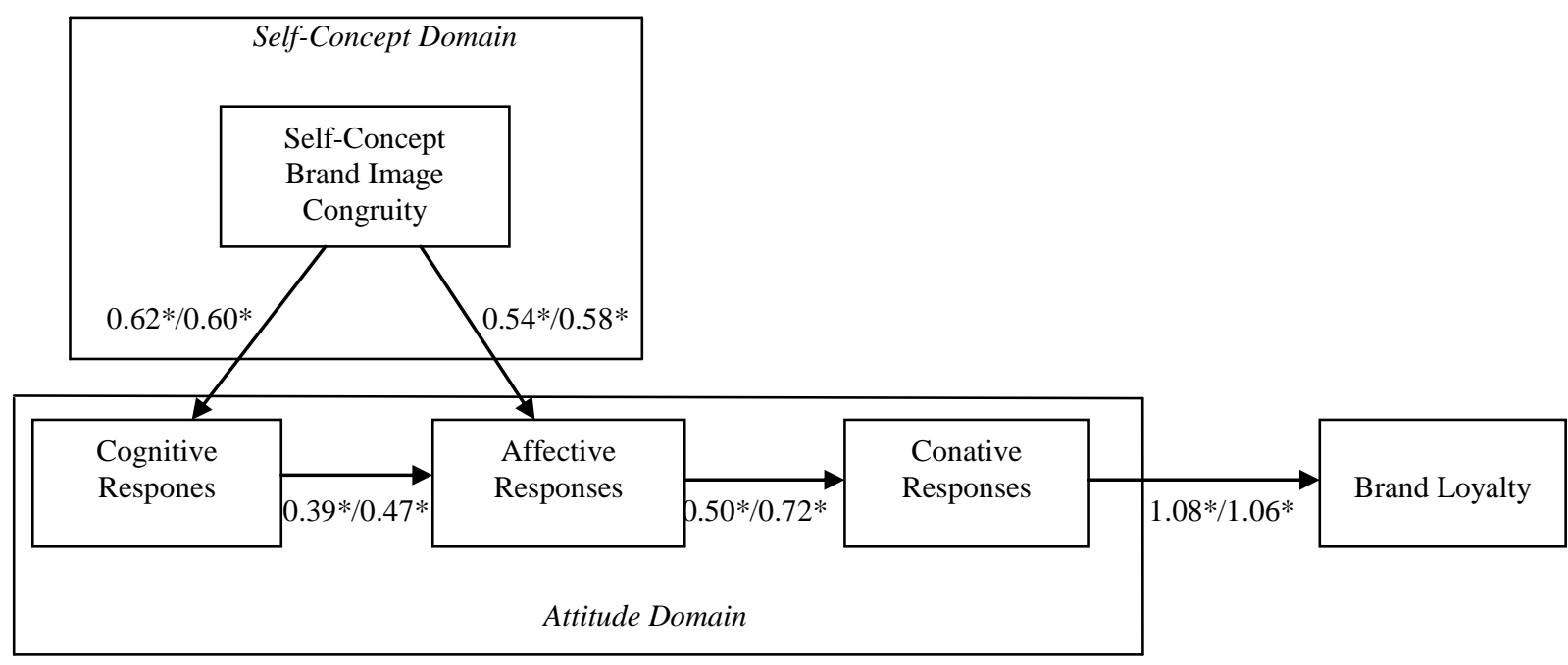

Figure 2: Empirical Findings for Hedonic and Utilitarian Products

1. * significant at $p<0.05$

2. Left gamma and beta coefficients for denim jeans; Right gamma and beta coefficients for wallets.

All coefficients are standardized.

\section{GENERAL DISCUSSION AND CONCLUSIONS}

The purpose of this study was to propose and test a model of brand loyalty which consists of a self-concept domain, an attitude domain, and behavioral outcomes; to assess this model across two different types of products (i.e., hedonic, utilitarian); and to investigate the differing moderating roles of gender within each product type. This study shows that self-concept brand image congruity positively influences consumer attitude, particularly cognition and affect, and that attitude-based behavioral intentions lead to brand loyalty behaviors. Importantly, this model is significantly robust to explain the formation of brand loyalty across two distinctly different types of products.

These findings are important from a theoretical perspective in that they illustrate the pervasive outcomes of self-concept brand image congruity. Regardless of whether a product is hedonic or utilitarian in nature, self-concept brand image congruity leads to more favorable product beliefs and affect towards the product in question. These results are particularly insightful in regards to utilitarian products. Specifically, although utilitarian products typically lack the potential to inspire consumer affect, the effects of self-concept brand image congruity are sufficiently strong to evoke such pleasurable consumer emotions. Therefore, self-concept brand image congruity can serve as a vehicle to stronger consumer-brand relationships.

Perhaps most importantly, this study highlights the role of gender in the creation of brand loyalty. Findings show that although brand loyalty can be achieved for both males and females in the face of self-concept congruities, 
the mechanism that achieves such brand loyalty is very different between genders and depending upon product type. In regards to hedonic products, females' tendency to access their emotions to a greater extent than males results in a significantly stronger link between affect and behavioral intentions on the part of females. It was theorized that such a variant effect would occur in the case of hedonic products due to the emotion-laden nature of these product types. While hedonic products are likely to arouse positive emotions in men and women, alike, women's tendency to be more attuned to their emotions than their male counterparts appears to enhance the impact of affect on their behavioral intentions. Therefore, pleasurable emotions towards hedonic products are a stronger driver to brand loyalty behaviors for women than for men.

Utilitarian products provide a different perspective in the manner in which brand loyalty is established between men and women. Since these product types are inherently low in their ability to elicit consumer emotions, it was anticipated that the effects of affect on behavioral intentions between gender would not differ. However, relationship theory suggests that females tend to seek out close relationships with others to a greater extent than do males (Gabriel and Gardner 1999). Continuing, females are more likely to include social relationships as an important component of their own self-concepts than are males (Markus and Kitayama 1991), directly linking others with their own self-concepts (Gabriel and Gardner 1999). Extending these notions to consumer-brand relationships led to the expectation that women would seek to attain closer consumer-brand relationships than would males, and that females would utilize self-concept brand image congruity as a mechanism to achieve this. Results showing significantly stronger effects of self-concept brand image congruity on cognition and affect for females than for males support this contention.

This study provides key managerial insights in the creation of brand loyalty among males and females, as well as within different product types. For hedonic products, managers should strive to continue to link consumers to their brands by stressing the pleasurable emotions that their brands can elicit. However, the fact that hedonic products are affect-laden provides managers with a more powerful opportunity to create loyal customers among females over males. By stressing the ability of hedonic products that are marketed to females to create pleasurable emotions, managers face a much stronger likelihood of instilling brand loyalty among their female consumers.

On the contrary, the effects of self-concept brand image congruity seem to play a paramount role in the creation of brand loyalty when considering utilitarian products. Importantly, gender differences occur within this domain as well. While self-concept brand image congruity appears to emerge as a vehicle for both male and female consumer to create strong consumer-brand relationships, this effect is stronger for females than males. Therefore, managers have a significant opportunity to encourage brand loyalty among females by creating brand images which closely mirror the self-concept of their female consumers and through marketing communication efforts that effectively communicates this congruity.

\section{AUTHOR INFORMATION}

Dr. Joseph F. Rocereto, Assistant Professor of Marketing at the Leon Hess Business School, Monmouth University, earned his Ph.D. from Drexel University. His research specializes in strategic branding, marketing communications, and managerial decision making. He has published in Journal of Business \& Economics Research, Advances in International Marketing, Advances in Consumer Research (ACR), and other North American and international conferences. E-mail: jroceret@monmouth.edu

Dr. Joseph B. Mosca, Associate Professor of Management in the Leon Hess Business School at Monmouth University earned his doctorate at NYU. Dr. Mosca specializes in Human Resource management, Human Relations, and active teaching methods, and is the recipient of seven teaching awards and three distinguished paper awards. His current research interests focus on developing hybrid courses, employee behavior, and jobs in the $21^{\text {st }}$ Century. E-mail: mosca@monmouth.edu. Corresponding author. 


\section{REFERENCES}

1. Ball, Dwayne A. and Lori H. Tasaki. 1992. "The Role and Measurement of Attachment in Consumer Behavior." Journal of Consumer Psychology 7 (2): 155-172.

2. $\quad$ Belk, Russell W. 1988. "Possessions and the Extended Self." Journal of Consumer Research 15 (September): 139-168.

3. Cole, L. and D. Sherrell. (1995). "Comparing Scales to Measure Compulsive Buying: An Exploration of Their Dimensionality.” In Corfman, K. and Lynch, J. (Eds.), Advances in Consumer Research, Vol. 22, Association for Consumer Research, Provo, UT: 419-427.

4. C Cross, Susan E. and Laura Madson. 1997. "Models of the Self: Self-Construals and Gender." Psychological Bulletin 122 (1): 5-37.

5. $\quad$ Cunningham, Scott M. 1966. "Brand Loyalty-What, Where, How Much?" Harvard Business Review 34 (January-February): 116-128.

6. $\quad$ Day, George S. 1969. "A Two-Dimensional Concept of Brand Loyalty." Journal of Advertising Research 9 (September): 116-128.

7. $\quad$ Dhar, Ravi and Klaus Wertenbroch. 2000. "Consumer Choice between Hedonic and Utilitarian Goods." Journal of Marketing Research 37 (February): 60-71.

8. $\quad$ Dick, Alan S. and Kunal Basu. 1994. "Customer Loyalty: Toward an Integrated Conceptual Framework." Journal of the Academy of Marketing Science 22 (2): 99-113.

9. Dolich, Ira J. 1969. "Congruence Relationships between Self-Images and Product Brands.” Journal of Marketing Research 6 (February): 80-84.

10. Fournier, Susan. 1998. "Consumers and Their Brands: Developing Relationship Theory in Consumer Research." Journal of Consumer Research 24: 343-373.

11. Gabriel, Shira and Wendi L. Gardner. 1999. "Are There 'His' and 'Hers' Types of Interdependence? The Implications of Gender Differences in Collective Versus Relational Interdependence for Affect, Behavior, and Cognition." Journal of Personality and Social Psychology 77 (3): 642-655.

12. Grubb, Edward L. and Harrison L. Grathwohl. 1967 "Consumer Self-Concept, Symbolism and Market Behavior: Theoretical Approach." Journal of Marketing 31: 22-27.

13. Hirschman, Elizabeth and Morriss B. Holbrook. 1982. "Hedonic Consumption: Emerging Concepts, Methods and Propositions." Journal of Marketing 48 (Summer): 92-101.

14. Hong, Jae E. and George M. Zinkhan. 1995. "Self-Concept and Advertising Effectiveness: The Influence of Congruency, Conspicuousness, and Response Mode." Psychology \& Marketing 12 (1): 53-77.

15. James, William. 1890. The Principles of Psychology. New York: Henry Holt.

16. Kahn, Barbara E., Manohar U. Kalwani, and Donald G. Morrison. 1986. "Measuring Variety Seeking and Reinforcement Behaviors Using Panel Data." Journal of Marketing Research 23 (May): 89-100.

17. Kleine, Susan Schultz, Robert E. Kleine, III, and Chris T. Allen. 1995. "How is a Possession "Me" or "Not Me"? Characterizing Types and an Antecedent of Material Possession Attachment." Journal of Consumer Research 22 (December): 327-343.

18. Kuebli, Janet and Robyn Fivush. 1992. "Gender Differences in Parent-Child Conversations about Past Emotions." Sex Roles 27: 683-698.

19. Kuebli, Janet, Susan Butler, and Robyn Fivush. 1995. "Mother-Child Talk about Past Emotions: Relations of Maternal Language and Child Gender over Time." Cognition and Emotion 9: 265-283.

20. Maccoby, Eleanor, E. 1990. "Gender and Relationships: A Developmental Account." American Psychologist 45: 513-520.

21. Malatesta, Carol Z., Clayton Culver, Johanna Rich Tesman, and Beth Shepard. 1989. "The Development of Emotion Expression During the First Two Years of Life." Monographs of the Society of Research in Child Development 50 (1-2, Serial No. 219).

22. Markus, Hazel Rose and Shinobu Kitayama. 1991. "Culture and the Self: Implications for Cognition, Emotion, and Motivation." Psychological Review 98: 224-253.

23. Oliver, Richard L. 1999. "Whence Consumer Loyalty?" Journal of Marketing 63 (Special Issue): 33-44.

24. Petty, Richard E. and John T. Cacioppo. 1986. Communication and Persuasion: Central and Peripheral Routes to Attitude Change. New York: Springer-Verlag. 
25. Petty, Richard E., John T. Cacioppo, and David Schumann. 1983. "Central and Peripheral Routes to Advertising Effectiveness: The Moderating Role of Involvement." Journal of Consumer Research 10 (September): 135-146.

26. Richins, Marsha L. 1994. "Valuing Things: The Public and Private Meanings of Possessions." Journal of Consumer Research 21 (December): 504-521.

27. Sirgy, Joseph M. and Coskun A. Samli. 1985. "A Path Analytical Model of Store Loyalty Involving SelfConcept, Store Image, Geographical Loyalty, and Socioeconomic Status." Journal of Academy of Marketing Science 13 (3): 265-291.

28. Srinivasan, Srini S., Rolph Anderson, and Kishore Ponnavolu. 2002. "Customer Loyalty in E-Commerce: An Exploration of its Antecedents and Consequences." Journal of Retailing 78: 41-50.

29. Strahilevitz, Michal and John G. Meyers. 1998. "Donations to Charity as Purchase Incentives: How Well They May Depend on What You Are Trying to Sell." Journal of Consumer Research 24 (March): 434-446.

30. Tellis, Gerard J. 1988. "Advertising Exposure, Loyalty, and Brand Purchase: A Two-Stage Model of Choice." Journal of Marketing Research 25 (May): 204-212.

31. Voss, Kevin E., Eric R. Spangenberg, and Bianca Grohmann. 2003. "Measuring the Hedonic and Utilitarian Dimensions of Consumer Attitude." Journal of Marketing Research XL (August): 310-320.

32. Wallendorf, Melanie and Eric J. Arnould. 1988. "My favourite Things: A Crosscultural Inquiry into Object Attachment, Possessivenes, and Social Linkage." Journal of Consumer Research 14 (March): 531-547.

33. Wylie, Ruth. 1961. The Self-Concept. Lincoln, Nebraska: The University of Nebraska Press.

34. Zeithaml, Valarie A., Leonard L. Berry, and A. Parasuraman. 1996. "The Behavioral Consequences of Service Quality." Journal of Marketing 60 (April): 31-46. 


\section{APPENDIX}

\section{Self-Concept Brand Image Congruity Scale Items}

1. This brand fits my personal image of who I am.

2. This brand helps me make a statement of who I am.

3. Using this brand reminds me of who I am as an individual.

4. This brand symbolizes a part of who I am as an individual.

5. This brand communicates to others a part of who I am as an individual.

\section{Cognitive Responses Scale Items}

1. I believe that this brand is of higher quality than other brands of wallets.

2. I believe that the look of this brand is popular these days.

\section{Affective Responses Scale Items}

1. I feel good when I use this brand.

2. Using this brand gives me pleasure.

3. Using this brand puts me in a good mood.

\section{Behavior Intentions Scale Items}

1. I am likely to purchase brands other than my preferred brand for myself in the future.*

2. If my favorite store did not have my preferred brand in stock, then I would purchase a brand other than my preferred brand for myself.*

\section{Brand Loyalty Scale Items}

1. I have recommended this brand to a friend over the past year.

2. I have traveled to another store to purchase my preferred brand when my favorite store was out of stock of my preferred brand.

Note:

1. All items with a 7-point Likert-type scale ( 1 = "strongly disagree"; 7 = "strongly agree")

2. * reversed item 